This PDF is a selection from an out-of-print volume from the National Bureau of Economic Research

Volume Title: Frontiers in Health Policy Research, Volume 3

Volume Author/Editor: Alan M. Garber, editor

Volume Publisher: MIT Press

Volume ISBN: 0-262-57141-2

Volume URL: http://www.nber.org/books/garb00-1

Publication Date: January 2000

Chapter Title: Regional Inequality in Medicare Spending: The Key to Medicare Reform?

Chapter Author: Jonathan Skinner, John E. Wennberg

Chapter URL: http://www.nber.org/chapters/c9830

Chapter pages in book: (p. 69 - 90) 


\title{
Regional Inequality in Medicare Spending: The Key to Medicare Reform?
}

\author{
Jonathan Skinner, Department of Economics, Dartmouth College \\ Center for Evaluative Clinical Sciences, Dartmouth Medical School \\ National Bureau of Economic Research
}

John E. Wennberg, Center for Evaluative Clinical Sciences and Department of Family and Community Medicine, Dartmouth Medical School

\section{Executive Summary}

Medicare expenditures per capita vary widely across different parts of the country. Average fee-for-service per capita expenditures in 1995/96 were $\$ 3,420$ in Eugene, Oregon, $\$ 3,663$ in Minneapolis, $\$ 7,847$ in Miami, and $\$ 8,861$ in McAllen, Texas. These measures are adjusted for differences across regions in the age, sex, and racial composition of the population, as well as differences in the underlying cost of health care. In this paper, we focus on these geographical variations in the Medicare program and argue that they are central to any proposed reform of the Medicare system. The first question that must be addressed is, are these expenditures higher in high-cost areas because the elderly population there is sicker? The answer is, largely no. Many of the areas with the highest levels of spending have similar underlying disease burdens to regions with low levels of spending. Nor does quality of care or patient satisfaction appear to be better in the high-expenditure areas. These disparities bring up a number of issues related to equity across regions, efficiency of Medicare spending, and the potential for funding Medicare reform. Reducing the intensity of care in high-expenditure regions can fund prescription drug benefits for the entire Medicare population, or extend the solvency of the Medicare trust funds by ten years, without obvious adverse implications for the health or satisfaction of the elderly population.

A somewhat surprising characteristic of the Medicare system is the extent to which per-capita Medicare payments vary across regions. Average 1995-96 fee-for-service Medicare per-capita expenditures were $\$ 3,420$ in Eugene, Oregon; $\$ 3,663$ in Minneapolis; $\$ 7,847$ in Miami; and $\$ 8,861$ in McAllen, Texas. These amounts are all adjusted for age, sex, race, and regional price differences. ${ }^{1}$ The existence of these variations is well-understood in the health policy community in Washington, D.C., and is particularly well understood by managed care companies whose Medicare capitated payments are indexed to these regional costs. Why these variations exist at all is less well understood. 
Recent proposals for Medicare reform have struggled with geographical differences in Medicare spending. For example, the Breaux-Thomas plan developed under the auspices of the National Bipartisan Commission on the Future of Medicare proposed a premium support program to replace the current Medicare system. ${ }^{2}$ Under premium supports, elderly Medicare enrollees would choose from a menu of private health insurance carriers and a government fee-for-service plan, with the premium costs being paid for in part (or entirely) by Medicare. In the proposal's summary, there was no mention at all of how the premiums would be adjusted for regional circumstances. Would they be benchmarked to national levels, or would the premiums be high in Miami and low in Minneapolis? It was clear that the Bipartisan Commission understood the issue. In a supporting document, the issues were set forth quite clearly:

Whether the government contribution is linked to average Medicare plan premiums in the county, metropolitan area, the nation, or some other area depends on whether the government wishes to reflect the variation that exists across regions of the country. The contribution might be adjusted for geographic differences such as local labor rates and local prices for goods and services, but not adjusted for variations such as differences in provider practice patterns or other unexplained utilization differences. ${ }^{3}$

In this article, we focus on these geographical variations in the Medicare program and argue that they should be central to any proposed reform. We suggest that Medicare expenditures-whether for premium support programs, the current fee-for-service system, or Medicare managed care-should be adjusted for geographic differences such as local labor rates, local prices for goods and services, and even the general health of the community. After adjusting for these factors, however, an enormous amount of variation, the so-called unexplained residual, has been difficult to account for. Is it simply reflecting unmet health needs, or preferences, or physical practice patterns? And does the extra "residual" spending actually lead to better quality of care?

We consider these questions below. First, we argue that a modest degree of regional variation in Medicare spending is caused by health differences. Elderly citizens of Huntington, West Virginia, are indeed sicker on average than those in Grand Junction, Colorado, and for this reason Medicare spending should be higher in Huntington. However, health differences explain only a small fraction of the total variation in Medicare expenditures across regions in the United States; a larger 
fraction of the unexplained residual appears to be related to patterns of general medical care by providers. ${ }^{4}$ These patterns of intensity are reflected best in how Medicare patients are treated in the last six months of life. By focusing on Medicare enrollees near death, we can effectively control for differences across regions in underlying health needs. Indeed, it turns out that indicators of the intensity of care in the last six months-such as the average number of physician specialist visits-are largely uncorrelated with indicators of community health levels but are highly correlated with Medicare spending. In short, we find that treatment patterns in the last six months of life are good instruments for general medical practice patterns in the region.

The next important question is whether the government should accommodate regional spending disparities by tying future payments to current (different) average per-capita spending levels. We argue that, along a number of dimensions, practice patterns in low-cost areas compared to high-cost areas yield similar quality in terms of both patient survival and quality of care; indeed there is some evidence that patient satisfaction may be higher in low-intensity areas. These regional disparities also bring up issues of equity: to the extent that elderly people in Minnesota and in Miami have paid similar amounts of taxes into the Medicare system, why should the elderly in Miami get so much more in revenue? ${ }^{5}$

Finally, we suggest that these regional variations in Medicare spending should be considered part of any Medicare reform simply because the fiscal implications of reducing regional inequalities can save billions of dollars in Medicare expenditures. A simple program that reduces the intensity of health care to levels consistent with 20 percent of regions in the United States would extend the solvency of the Part A trust fund an extra 10 years, to $2025 .^{6}$

\section{The Nature of the Problem}

In this section, we consider first the extent of variations in Medicare spending. We rely on data in the Dartmouth Atlas of Health Care (Wennberg and Cooper, 1997, 1999) for much of our data discussion. The atlas developed geographic cachement areas that reflected actual migration patterns of the Medicare population. Each hospital referral region (HRR) was defined as an area with at least one major hospital that performed cardiovascular procedures. Nearly every zip code in the United States was then assigned to an HRR depending on the 
discharge patterns of the Medicare patients. Attempts were made in the final assignment to preserve contiguous borders for the HRR, but in a few cases, migration patterns were sufficiently strong to cause an HRR to be split. ${ }^{7}$ All calculations of rates presented below were assigned by location of residence and not where the service was actually performed. For example, if an individual from Arlington, Virginia, went to the University of Virginia hospital in Charlottesville, the Medicare charges would be attributed to the Arlington HRR, not the Charlottesville HRR. Thus, the atlas definition of rates by zip code of residence avoids the kinds of selection bias problems that occur when a particular area (like Boston) attracts large numbers of patients from distant areas. To control further for regional differences not related to health care, we price-adjust Medicare spending to remove the fact that New York City hospitals and physicians are paid more per procedure than those in Enid, Oklahoma. ${ }^{8}$

Figure 3.1 shows a map of the 306 HRRs in the United States, with the accompanying quintile of HRR-level Medicare spending, adjusted for regional differences in age, sex, and race. ${ }^{9}$ There is considerable variation in per-capita Medicare spending across state: sixty-two regions in the United States spend less than $\$ 4,178$ per person, while sixty-one regions spend more than $\$ 5,698$, ranging up to nearly $\$ 8,000$ in regions like Miami and Baton Rouge, Louisiana.

What is it about the high-cost areas that makes them high-cost? This question has been the topic of debate for many years. Some view these higher costs as arising from differences in preferences or in underlying health needs. ${ }^{10}$ Any correlation between health care resources, such as hospital beds or physician supply, and overall utilization rates is the consequence of "demand-induced demand," or health care resources moving to areas with the greatest demand.

Others, like those in the "supplier-induced demand" literature, have viewed the reason for these differences as related to physician behavior: some areas just have more doctors, and those doctors maximize utility by doing more procedures and thus generating a larger revenue (Labelle, Stoddart, and Rice 1994; Auster and Oaxaca 1981; see also Wennberg and Gittelsohn 1982). More recently the "supplier-induced demand" model has been augmented by the idea that some physicians show greater "enthusiasm" for surgical procedures (Chassin 1993). We want to draw a distinction here between "enthusiasm" for specific surgical procedures and the general intensity of medical care. Surgical enthusiasm may not be closely correlated with overall levels of Medicare spending; as noted above, rates of carotid endartectomy are actually 


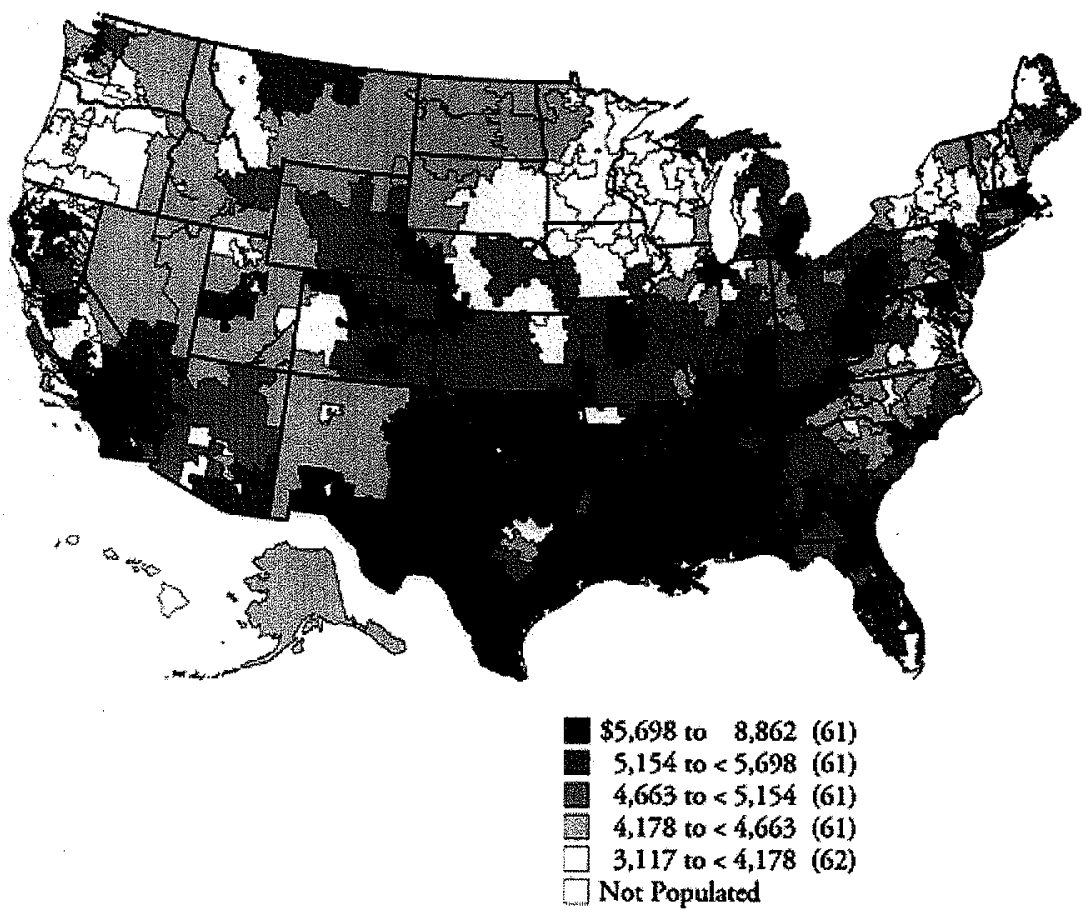

Figure 3.1

Price-adjusted reimbursements for noncapitated Medicare expenditures per capita by Hospital Referral Region (1996)

lower in Miami than in Minneapolis. Instead, we are interested in the treatment of chronic disease such as congestive heart failure or chronic obstructive pulmonary disease (COPD) that accounts for a large fraction of overall Medicare dollars, particularly in the last six months of life.

While we cannot sort out the various theories, it is clearly important to distinguish between health-related reasons for variations in Medicare spending and those related to provider behavior. If the variation in Medicare spending observed across regions is the consequence of health-related demand, then such variation should be preserved, not erased. In the next section, we consider demand-driven reasons for the differences in health care costs across regions.

\section{Health-Based Differences in Regional Medicare Spending}

To characterize community-level health requirements or illness burden, we consider five "low-variation" conditions that are not strongly 
related to the supply of health care resources. Nearly every elderly person with a hip fracture, for example, is admitted to a hospital, and thus the incidence rate of hip fracture hospitalizations is a nearly perfect measure of the underlying population-level incidence. Hip fracture rates vary little across regions and are likely related to long-term nutritional habits. The incidence of hospitalization for wrist or ankle fractures, on the other hand, is not a good measure of the underlying health care demand because these fractures are highly variable across regions and are likely related in part to practice patterns of physicians (Wennberg and Cooper, 1999). Other indicators of underlying health status are age-sex-race-adjusted rates of heart attacks (acute myocardial infarction, or AMI), strokes, gastrointestinal bleeding, and colon cancer. All these events generally lead to hospitalization, so hospitalization records provide a good measure of population-level incidence. In addition, we also include the percentage of the elderly who are functionally disabled as reported in the 1990 census. ${ }^{11}$ Means and standard deviations are presented in column 1 of table 3.1.

Our strategy is first to show that these indicators of community-level disease burdens are strong predictors of mortality. There is considerable variation in age-sex-race-adjusted mortality rates in the elderly population, ranging from less than forty per thousand in Sun City, Arizona, to more than sixty per thousand in Slidell, Louisiana, and Huntington, West Virginia. In the second column of table 3.1, we measure how much of this regional variation in mortality is associated with our indicators of health. ${ }^{12}$ All regressions are weighted by the Medicare population, and $t$-statistics are estimated using the Huber-White heteroscedasticity-consistent approach. All illness levels show a strong positive correlation with generally significant results; the overall $R^{2}$ is 0.48 , which means that nearly half of the variation in mortality rates are explained by these health indicators. Note that the coefficients in this regression should be interpreted not simply as the mortality rates from those diseases but also as the extent to which the disease indicators are correlated with other illness that, in turn, affect mortality.

Column 3 of table 3.1 shows how Medicare expenditures per capita are associated with these indicators of community health. Generally, there is a positive association with illness rates and Medicare expenditures; an increase in the rate of gastrointestinal bleeding of 0.1 percent (or one per thousand) is associated with an increase in Medicare spending of $\$ 209$ per capita. This statement seems to imply that, in a group of 1,000 people, an extra case of GI bleeding is associated with an increase 


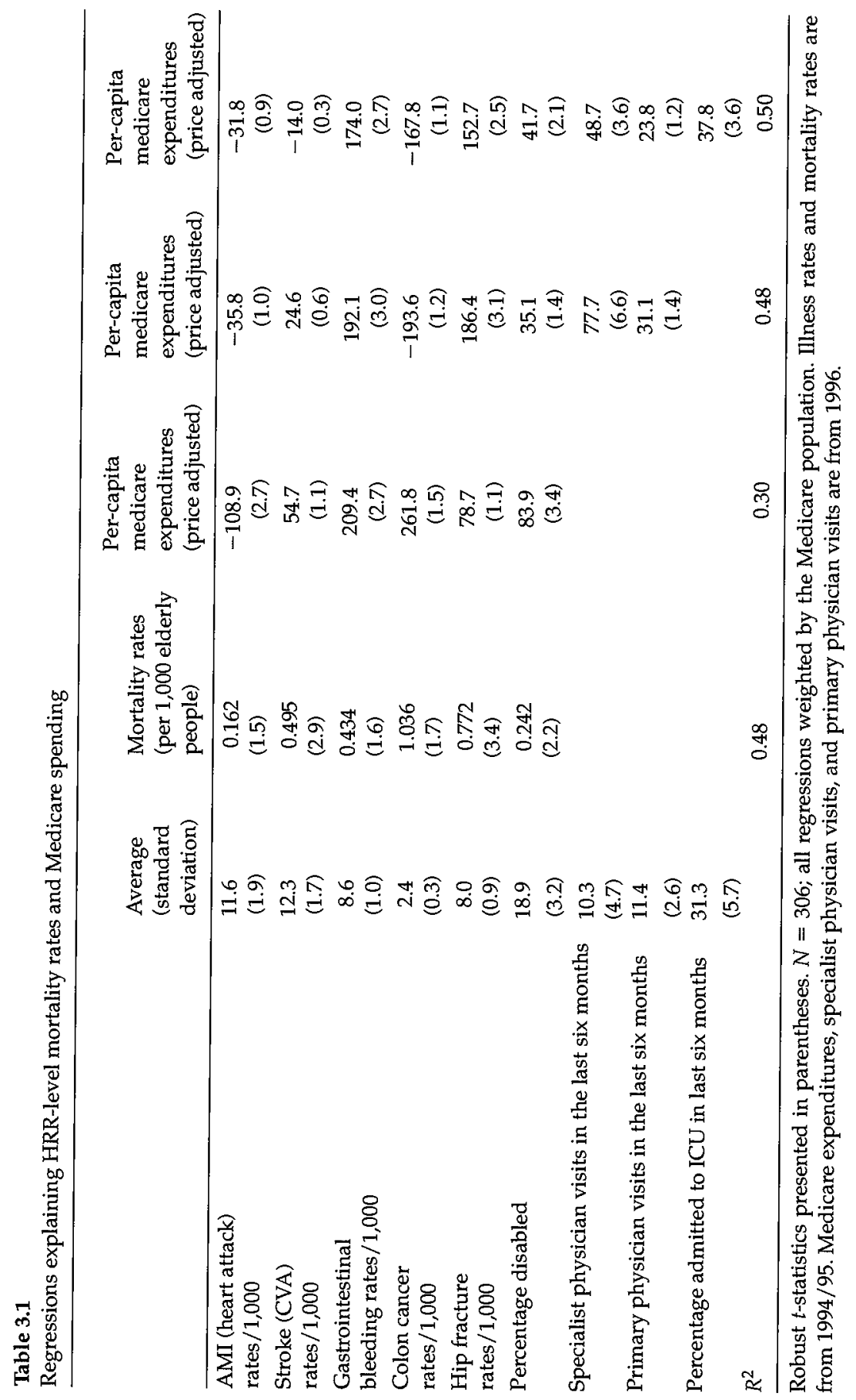


in Medicare expenditures of $\$ 209,000$ ( $\$ 209$ times 1,000 people). The magnitude of the effect-much larger than the actual cost of GI bleeding-suggests that regions with higher GI bleeding rates are also likely to suffer from other diseases that tend to increase health care costs. On the other hand, the coefficients must also be interpreted with caution, as suggested by the negative coefficient on heart attacks (AMI). The rate of AMI may be correlated with other factors affecting Medicare spending, so the negative coefficient is a reminder that we are not estimating a conventional risk adjustment measure. ${ }^{13}$ Still, despite the low $R^{2}$ of 0.30 , we find evidence of illness-based differences in Medicare spending. ${ }^{14}$

We created an illness adjustment factor by taking the predicted level of Medicare spending in column 3 of table 3.1 and dividing the predicted level by the average level in the United States. For example, our illness adjustment is 1.20 in Birmington, Alabama, which means that Medicare expenditures there are predicted to be 20 percent higher than the U.S. average predicted simply on the basis of their higher levels of disease burden..$^{15}$ By contrast, Mesa, Arizona, would receive 15 percent below average because of better than average health status. This approach does have its flaws because (as noted above) it may be adjusting spending on the basis of non-health-related factors, but it does provide a measure of the "upper bound" in terms of the explanatory power of health-related indicators for overall Medicare spending. ${ }^{16}$

Previous research has also followed this decompositional approach to explaining Medicare benefits. In a recent article Cutler and Sheiner (1999) explained a larger fraction of the regional variation in Medicare spending by including demographic factors, such as the female percentage of the population and the percentage of Hispanic and African-American members, as well as resource factors. Because their measure of Medicare spending was already adjusted by sex and race (at least for African-Americans and non-African-Americans) for micro-level differences in spending, the causal paths by which these regional demographic factors affect the demand (or supply) of Medicare spending is not well understood. ${ }^{17}$

\section{Practice Patterns in the Last Six Months of Life}

We have adjusted for several important factors to explain overall Medicare per-capita expenditures, but there is still considerable varia- 
tion in Medicare spending even after controlling for these factors. In this section, we focus on one measure of medical health care intensity: treatment patterns in the last six months of life. We argue that regions with a higher number of physician visits in the last six months of life tend to be those with more aggressive health care intensity as measured by substantially higher levels of per-capita expenditures in the entire Medicare population. At best, however, they are correlated weakly with underlying health status (Wennberg and Skinner, 1999). Our index of mortality in column 2 of table 3.1, for example, explains just 2 percent of the variation in end-of-life specialist visits. This figure suggests to us that treatment patterns in the last six months of life reflect provider-level attitudes toward the appropriate level of health care intensity for chronically ill patients that are independent of the underlying patterns of illness or poor health in the community. ${ }^{18}$

Figure 3.2 shows the variation in the number of visits by specialists per individual in their last six months of life (age-sex-race-adjusted). In Miami, for example, there were 25.1 visits per decedent, 22.9 in Los Angeles, and 23.8 in Newark, New Jersey. By contrast, in the Minneapolis HRR, there were just 3.8 visits per decedent; in Mason City, Iowa, there were 2.0 visits, and in Lebanon, New Hampshire, there were 2.6 visits (the average is 10). In part, some of the difference may be explained by urban versus rural areas: the overall costs of seeing a specialist is probably lower in Miami than in Mason City. But the magnitude of the differences is remarkable.

Maybe regions with high levels of physician visits substitute outpatient care for inpatient care. However, regions with high levels of specialist visits in the last six months of life also tended to experience above-average use of intensive care units. The percentage of people in their last six months of life who were admitted to an ICU was 49 percent in Miami but only 23 percent in Minneapolis; the correlation coefficient between specialist visits and ICU admissions was 0.62 .

We expand our previous regression of Medicare expenditures by adding two more variables: the average number of primary care physician visits in the last six months of life, and the average number of specialist visits in the last six months. As shown in column 4 of table 3.1, Medicare spending is highly correlated with specialist visits in the last six months of life (with the $R^{2}$ rising to 0.48 ). The coefficient for primary care visits is positive but is not significant at conventional levels. Column 5 of table 3.1 includes the percentage of elderly people admitted 


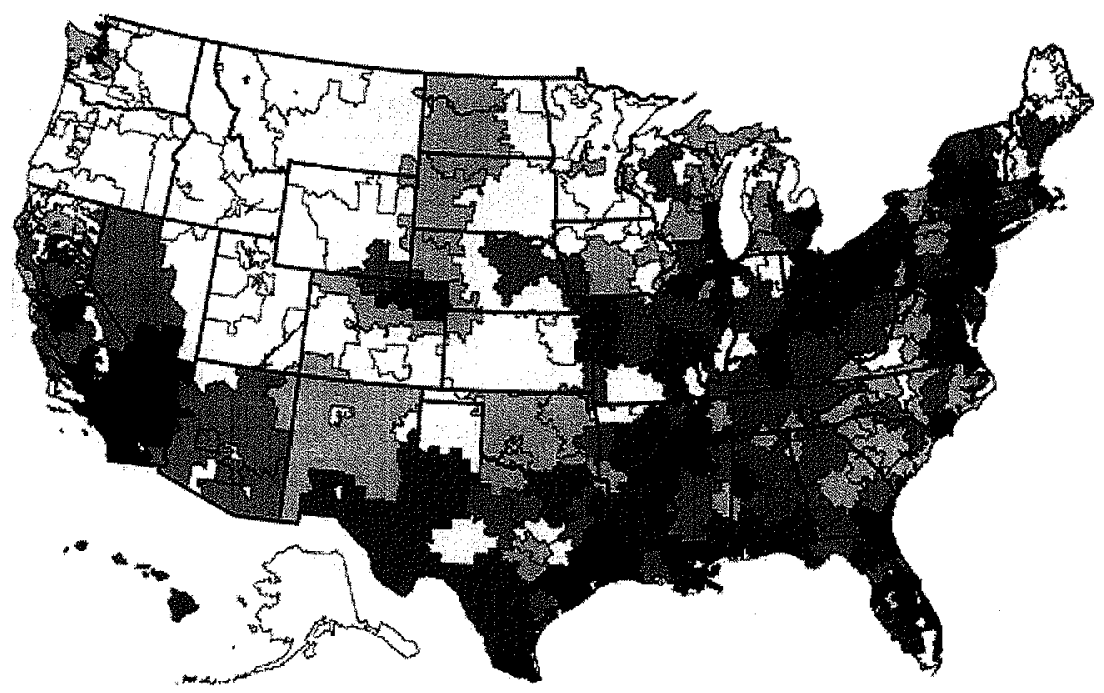

21.7 to $35.8(60)$

18.1 to $21.7(63)$

16.1 to $18.1(65)$

14.4 to $16.1(58)$

7.4 to $14.4(60)$

Not Populated

Figure 3.2

Average number of physician visits per decedent in the last six months of life by Hospital Referral Region (1996)

to an ICU in their last six months. Again, this indicator is highly predictive for the pattern of Medicare spending in the entire population and not just for those in their last six months.

When we focused on just specialist visits, we used a more nonparametric approach to estimating how specialist visits in the last six months were related to overall Medicare spending. We first create deciles of regions depending on their average number of specialist visits in the last six months of life. For example, the bottom decile (decile 1) comprised HRRs with 10 percent of the elderly population. Among these HRRs, the average number of specialist visits in the last six months was 4.1. In the top 10 percent of the population (decile 10), the average number of specialist visits was 20.6. We then regressed Medicare spending against the illness indicators and dummy variables for each of the deciles, with the results shown graphically in figure 3.3. ${ }^{19}$ There is a strong and nearly monotonic relationship between spe- 


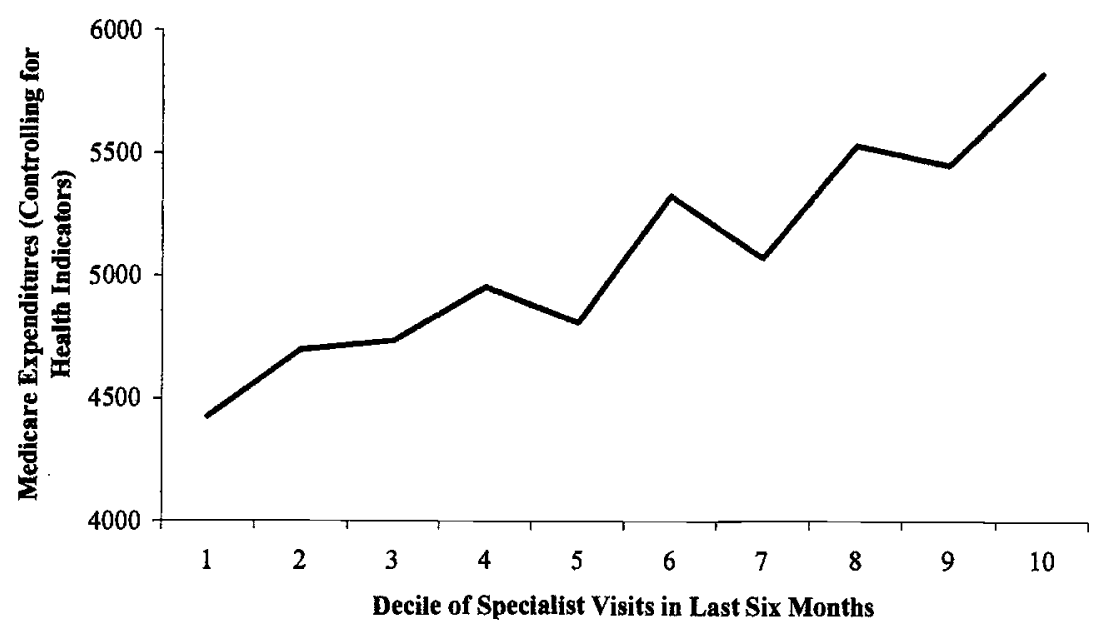

Figure 3.3

Relationship between specialist visits in the last six months of life and Medicare spending

cialist visits in the last six months and overall spending, with predicted Medicare spending equal to $\$ 4,426$ in the bottom decile and $\$ 5,823$ in the top decile. These estimates control for differences in health status across regions. ${ }^{20}$

We have suggested that these variations in overall per-capita Medicare expenditures are the consequence of differences in practice intensity. An alternative explanation is that preferences across regions are different; in some areas, individuals prefer to receive more intensive care, including more intensive care near death. According to this alternative explanation, variations are "demand-induced" by patients rather than "supply-induced" by health care providers.

A recent study sheds some light on this debate. The SUPPORT study was a large, multi-center effort first to discern preferences about end-of-life care among patients and then to implement advanced-care directives to ensure that patient preferences were realized (SUPPORT 1995). Despite the best efforts of investigators to implement individual patient preferences, the study had little success. For example, patients who stated that they would prefer an out-of-hospital death "very much" were more likely to die in a hospital than patients who did not prefer an out-of-hospital death, holding health and demographic factors constant (although the differences were not significant). The only 
factor that did predict whether individuals died in the hospital was the overall supply of hospital resources in the region (Pritchard et al. 1998). ${ }^{21}$ That is, preferences of patients for what kind of death they preferred counted for nothing; what did matter was the propensity of health care providers in that region to hospitalize their patients.

\section{But Do More Resources Lead to Better Quality Care?}

Until this point, we have argued that much of the observed differences in Medicare spending across regions is the consequence of variation in practice patterns, particularly with respect to the treatment of chronic disease. Of course, if the additional spending resulted in improved outcomes or better quality care, one might hesitate to scale back high-cost areas and suffer a loss in health outcomes as a consequence. We do not address this quite complicated question directly but instead consider the evidence from related studies both with respect to Medicare spending, survival rates, and the provision of preventive care with wellestablished clinical benefit.

There is increasing evidence that, for many intensive forms of medical care, the benefits are small or even negative (e.g., McClellan, McNeil, and Newhouse 1994; Conners et al. 1996). In related research, we have argued that there does not appear to be any relationship between more intensive care and better survival patterns; this observation holds for overall mortality rates (Fisher et al. 2000; Wennberg and Skinner 1999) as well as for mortality in a sample of hip fracture patients (Chau, Fisher, and Skinner 1999).

We can also gain estimates of the regional process of care by estimating the percentage of elderly patients receiving appropriate preventive services, such as annual screening for mammography or immunization for pneumonia. Our initial hypothesis is that higher levels of Medicare spending should be reflected in better quality care because physicians have more opportunity to provide preventive services with proven clinical effectiveness (Wennberg and Cooper 1999). Figure 3.4 shows the percentage of women in the Medicare population receiving mammographies in 1996. Clearly, we should not expect 100 percent compliance, but it is likely that mammography rates below 20 percent are too low. There is no support for the initial hypothesis; if anything, there appears to be a negative correlation between per-capita Medicare expenditures and screening for breast cancer. A similar pattern is shown in 


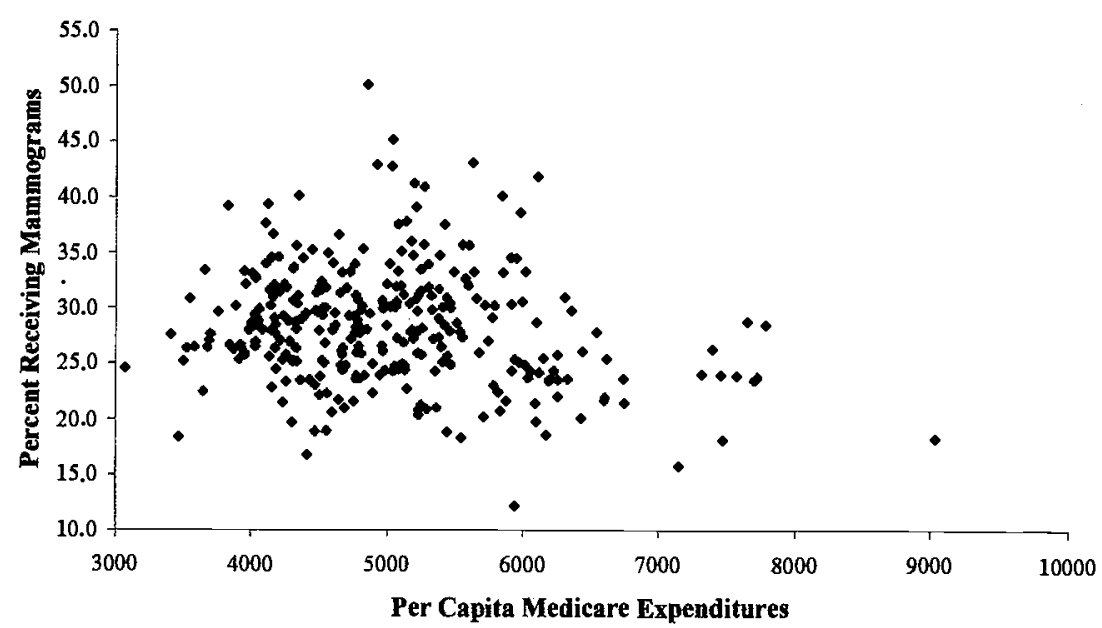

Figure 3.4

Percentage of women receiving mammograms, by regional per-capita Medicare expenditures

figure 3.5. Once again, there is a faintly negative correlation between overall per-capita Medicare expenditures and the rate of immunizations for pneumococcal pneumonia. Similar patterns hold for other forms of preventive screening, such as annual eye examinations for diabetics. ${ }^{22}$

It is difficult to find evidence that regions with higher levels of Medicare spending are associated with better health outcomes or a higher quality of care. Another possibility is that the observed variations in Medicare spending were the consequences of patient preferences. While the results from the SUPPORT study suggest that preferences do not determine regional differences in Medicare spending, we cannot rule out this explanation a priori. Even if preferences were to determine a large fraction of the observed variation, on the basis of equity or fairness, we question whether the Medicare system should be accommodating these preferences. Elderly people with similar ages and lifetime incomes have paid about the same amount into the Medicare system through payroll tax contributions and general tax revenue. Why should their benefits differ by a factor of 2 (Feenberg and Skinner 1999)? A reduction in geographical disparities could improve the overall fairness of the Medicare system in addition to having first-order implications for the financial health of the Part A trust fund. 


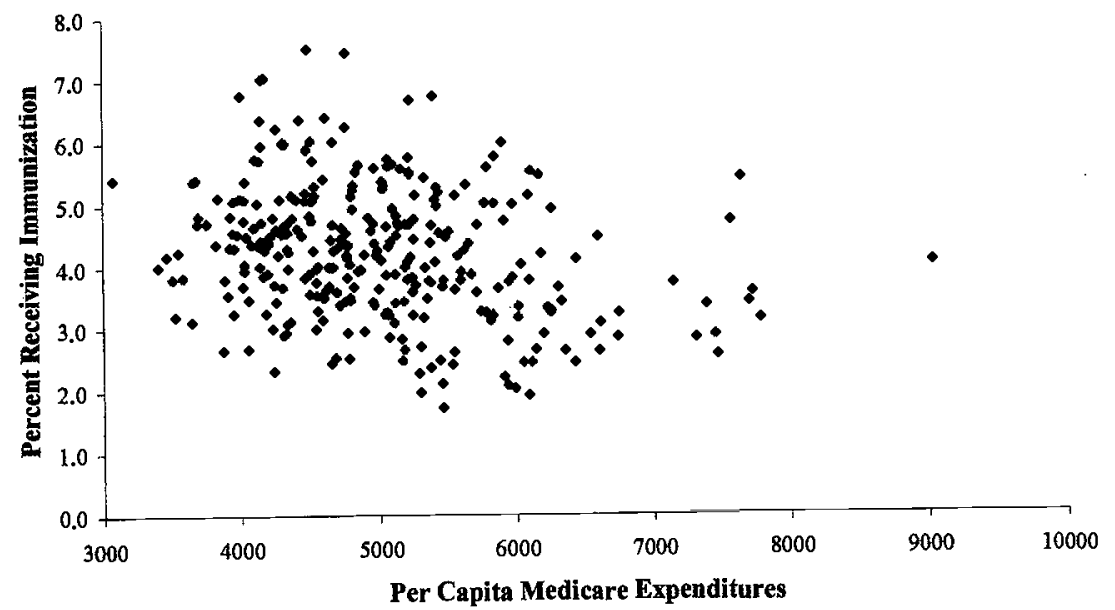

Fỉgure 3.5

Percentage of elderly receiving immunization against pneumococcal pneumonia, by regional per-capita Medicare expenditures

\section{Budgetary Implications of Reducing Regional Differences in Medicare Expenditures}

In this section, we consider a specific reform that uses the illness adjustment mechanism for benchmarking the appropriate level of Medicare spending. First, we benchmark an "appropriate" level of Medicare spending as being the level of age-sex-race- and illness-adjustment per-capita expenditures observed in those regions where health care intensity-as measured by specialist visits in the last six months of life-is relatively low. Obviously, we could benchmark Medicare spending to regions like Minneapolis with very low levels of health care intensity and low levels of Medicare expenditures. Instead we adopt a more conservative approach, which is to benchmark Medicare spending to that level of Medicare spending experienced by one-fifth of the U.S. elderly population in low intensity areas. This approach implies a 10 percent reduction in overall Medicare spending. We adjust regional Medicare spending by the illness adjustment measure calculated above and set the level of Medicare spending to ensure a 10 percent cut in the overall budget. (If regions are below the benchmarked amount anyway, we leave them at that amount.) For example, the benchmarked expenditures in Birmingham, Alabama, are slightly less 
than actual expenditures $(\$ 5,514$ versus $\$ 5,709)$ because spending in Birmingham was not very high to begin with and the illness adjustment of 20 percent allowed for higher-than-expected levels of spending to treat the sicker population. By contrast, expenditures in Miami would experience a sharp decline, from $\$ 7,847$ to $\$ 5,028$. (Recall that these figures are in price- and age-sex-race-adjusted 1996 dollars, so the actual benchmark in Miami would be higher in nominal terms.)

The budgetary implications would be substantial. According to the Board of Trustees (1999), the Part A Medicare Trust Fund is predicted to deplete its current balances by 2015 according to intermediate projections. We considered how the trust fund would be affected by implementing our proposed reform for Medicare Part A expenditures beginning in 2000. In one case, the 10 percent aggregate reduction in expenditures would be implemented immediately; in another case, it would be phased in over a five-year period. Using the Board of Trustees' assumptions about payroll taxes, interest rates, and other factors, we found that reducing the regional variation in Medicare expenditures had a substantial impact on the trust fund balances. Figure 3.6 shows the intermediate trust fund predictions, with all values in constant 1999 dollars. Under the status quo, it becomes bankrupt in 2015 and (if allowed to borrow) would end in 2024 with a negative balance of $-\$ 562$ billion in 1999 dollars. ${ }^{23}$ By contrast, an immediate policy to reduce regional variation in Medicare spending would lead to a positive $\$ 180$ billion balance in the trust fund in 2024; even the gradual phase-in results in a positive $\$ 132$ balance in 2024.

The Part A trust fund may not be the best indicator of the long-term viability of Medicare, a point that even the Board of Trustees make (Board of Trustees, 1999). Another way to judge the value of reducing regional variation is to consider what the money thus saved would provide in different benefits. One proposal has been to fund drug benefits for Medicare enrollees, particularly those with low incomes. ${ }^{24}$ A 10 percent reduction in conventional Medicare spending (both Part A and Part B) could fund a drug benefit of approximately $\$ 20$ billion, enough to fund a general non-means-tested drug benefit. In short, the potential savings realized by reducing geographical variations in Medicare spending are sufficiently large either to extend the life of the Medicare Part A trust fund another ten years or to provide drug benefits for every Medicare enrollee. 


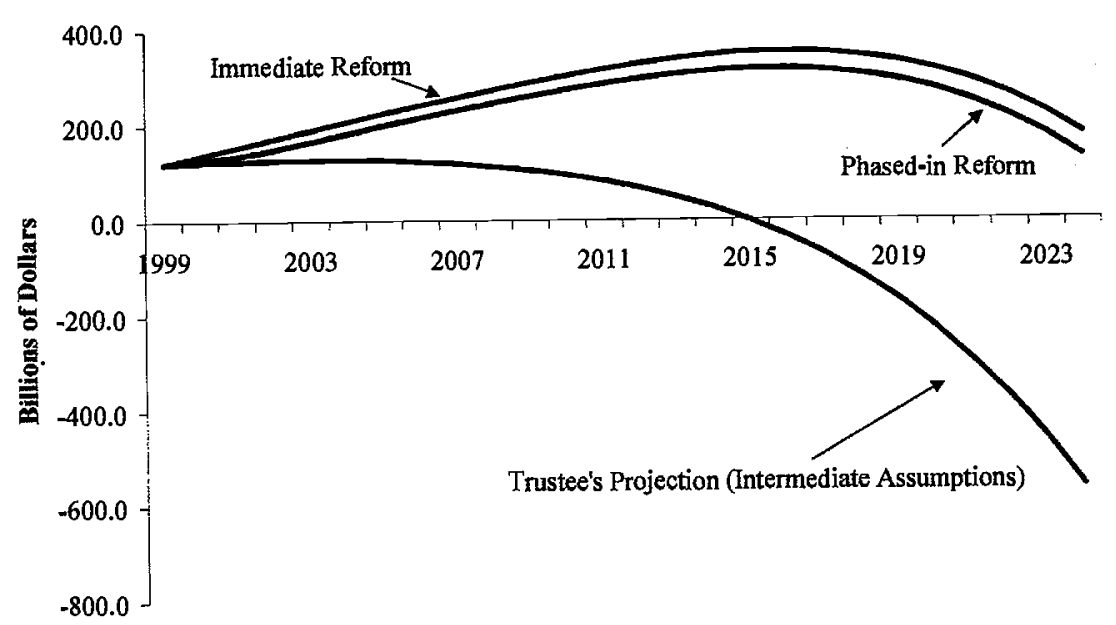

Year

Figure 3.6

Medicare Part A Trust Fund projections

\section{Discussion and Policy Implications}

It is useful at this stage to review the results. We have documented the wide variation in regional patterns of Medicare spending, and we have shown that these variations are not the consequences of differences in the age composition of the population or the idea that some areas are sicker than others. This additional spending doesn't appear to have measurable health benefits, nor is it likely to be explained by preferences. Finally, if the regional variation in Medicare spending does have little in the way of health benefits, attenuating regional disparities can fund the Medicare trust fund for an extra ten years or provide new pharmaceutical benefits for all enrollees. Thus, we argue that regional variations in Medicare expenditures should be central to any Medicare reform.

In theory, one might agree that there should be less variation across regions, but how can variations be reduced in practice? Two primary issues must be addressed. The first is, How might the Medicare system be changed to reduce such variation? The second is, How do we know that in the short-term, a relatively sudden change in the Medicare reimbursement system won't have an adverse impact on health?

One advantage of the premium support proposals suggested in the bipartisan commission's final report is that such support programs 
make regional variations transparent. If the support amounts were adjusted to preexisting levels of regional per capita expenditures, then elderly citizens in Minneapolis would figure out quickly that their dollar premium support was half the premium support in Miami. This transparency in turn could lead to a greater level of political awareness of elderly people in low-expenditure areas who are wondering why their Medicare premium support is so stingy, or why insurance companies are averse to providing many options in comparison to their counterparts in high-expenditure areas.

The premium support approach would also provide a straightforward approach to the national benchmarking of health costs along the lines suggested above. A gradual transition over a five-year period to a national benchmark (with adjustments for price and illness differentials) would be one way to implement such an approach. How insurance companies would react to attenuated regional differences in Medicare spending is not clear, however, because it would put them in the unpleasant position of convincing providers to scale back their customary high-intensity care patterns to lower intensity care.

One of the major concerns with the premium support approach has been its reliance on insurance companies to provide a menu of different options for the elderly. In the long-run, these options would likely involve a heavier reliance on managed care policies. Yet broad evidence suggests dissatisfaction, both from patients and from physician providers, with the managed care option (Simon et al. 1999). How might the cost savings from reducing geographical variation be gained even under the status quo, where fee-for-service accounts for the majority of Medicare enrollees?

One option is to tie Medicare reimbursements to the regional level of costs (after allowances for illness burdens and price level differentials). For example, Diagnostic-Related Groups (DRG) payments might be discounted by 20 percent, with the residual placed in an escrow account that is distributed at the end of the fiscal year depending on the overall regional level of reimbursements. This system is similar to the one now in place in Germany, where for some components of care, physicians earn nonmonetary "credits," which are then converted into payments at three-month intervals depending on the aggregate budget and the number of credits submitted (Kamke 1998). The incentive structure under fee for service does not directly address the problem that a few physicians may be quite aggressive in their treatment patterns because the relative advantage of prescribing more is still just as 
high under this system. Would physicians migrate to regions with higher per-unit reimbursement rates? Nevertheless, these regional budget caps represent one approach to keeping Medicare afloat for at least another decade.

The final question is how such short-term changes in the reimbursement mechanisms would affect the quality of care. Would the response of physicians to lower rates of reimbursements lead to more care being administered? Or would physicians be less willing to treat Medicare patients in high-use (and low-reimbursement-rate) areas, in much the same way that Medicaid patients experience limited access to private physician practices (Baker and Royalty 1999)? We do not know how short-term reforms of this type might affect health care outcomes and satisfactions. The potential benefits, in terms of both dollars saved and diminished geographical inequality, are sufficiently large and permanent to make answers to such questions worth investigating.

\section{Notes}

We relied heavily on the Dartmouth Atlas Working Group-and in particular the efforts of Tom Bubolz, Kristy Bronner, Elliott Fisher, Jim Poage, Sandra Sharp, and Therese Stukel-in developing the Atlas database. We are also grateful to participants at the NBER Conference on Frontiers of Health Economics for helpful comments, and to the Robert Wood Johnson Foundation and the National Institute on Aging for financial support.

1. These figures are for the fee-for-service population in the corresponding hospital referral region (HRR), which often includes a wider area than the boundary of the city. Because capitation payments for Medicare managed care are keyed to county-level fee-for-service payments, the average Medicare payment across all enrollees (fee-for-service plus managed care) is quite similar to these numbers.

2. However, the Commission did not approve the Breaux-Thomas proposal. See "Building a Better Medicare for Today and Tomorrow" (March 16, 1999), located at http://thomas.loc.gov/medicare/bbmtt31599.html.

3. "Key Issues in Considering a Premium Support Program for Medicare," http:/ / thomas.loc.gov/medicare/pssd31299.html.

4. Practice variations associated with the intensity of general medical care should be distinguished from practice patterns associated with specific surgical procedures. For example, the rate of carotid endartectomies in Miami is low relative to U.S. averages and is in fact lower than the rate in Minneapolis (Wennberg and Cooper 1999).

5. See McClellan and Skinner (1999), Skinner and Fisher (1997), and Feenberg and Skinner (1999).

6. Of course, considerable uncertainty is inherent in trust fund projections, so this ten-year projected extension is illustrative more than definitive (Lee and Skinner 1999). 
7. For example, the New Haven, Connecticut, HRR is split in two by a coastal region of Connecticut that migrates along Route 9 into Hartford. See Wennberg and Cooper (1999) for details.

8. The price adjustment is a variant of the GPCI price index developed by Zuckerman, Welch, and Pope (1990). The index depends on an index of office space costs and (nonmedical) professional salaries in the region. See Wennberg and Cooper (1999) for details of the price index.

9. The per-capita measures of Medicare spending have been adjusted for differences across regions in age, sex, and race by calculating age-sex-race-specific per-capita Medicare spending in each HRR and then weighting each of these cells to make the HRR consistent with the demographic composition in the U.S. elderly population.

10. For example, see Escarce, (1992, 1993), Stano and Folland (1988), Folland and Stano (1989), Gruber and Owings (1996), and Green and Becker (1994).

11. These are available at the zip code level (from CensusCD, www.censuscd.com) but were aggregated to the HRR level in this analysis.

12. The health and mortality data are from 1994/95; the mortality data are reported in Wennberg and Cooper (1997).

13. For a recent discussion of Medicare risk adjustment, see Kuttner (1998) and Iezonni et al. (1998) and the references therein.

14. We also included the overall mortality rate as an explanatory variable. It entered with a negative coefficient, however, suggesting that our indicators of health status capture much of the extra costs of people in their last six months of life.

15. Including mortality rates in the regression does not improve predictive value, and the coefficient on mortality is negative after controlling for the five indicators of health. However, the univariate correlation between mortality and our illness-adjusted measure of Medicare spending is positive.

16. The least-squares regression determines coefficients that essentially maximize the percentage of the variation to be explained by the independent variables.

17. For example, they find a positive association between the percentage of the population who are Hispanic and Medicare spending. As shown in figure 3.1, spending is particularly high in Texas and Florida, both states with large Hispanic populations. The question is, Are these regional patterns being driven by higher demand on the part of the Hispanic population or do Hispanics happen to live in areas with physicians who provide high levels of health care intensity?

18. Some elderly people die suddenly with little warning or health care expense. However, most people who die had chronic illness and frequent interactions with the health care system prior to death.

19. All decile dummy variable coefficients were significantly different from decile 1 (the bottom 10 percent).

20. A higher number of specialist visits in the last six months could be associated with higher per-capita Medicare expenditures. However, the magnitude of differences in spending on those in the last six months of life cannot come close to explaining the differences in overall per-capita Medicare spending because the last-six-months group make up only about 5 percent of the Medicare population. 
21. Either in terms of beds per thousand or hospital days per thousand residents.

22. Surprisingly, these indicators (and other indicators, such as annual eye examinations for diabetics) are not closely correlated across regions (Wennberg and Cooper 1999).

23. The Board of Trustees' report does not provide predictions of the trust fund beyond 2008. We used the intermediate-term predictions of growth rates in payroll taxes and expenditures, as well as an assumed nominal interest rate of 6.6 percent, (1) to match our generated trust fund estimate to the Board of Trustees' estimate through 2008, and (2) to predict the status quo and counterfactual trust fund amounts to 2024. Some brief technical notes: The interest rate of 6.6 percent was slightly above the nominal rate of 6.4 percent (a 3 percent real return and a 3.3 percent inflation rate implies a yield of $1.03 \times 1.033$ $=1.064$ ) but doing so matched the Board of Trustees' report balances more closely. And second, when growth rates were reported for, say, 2020, we assumed these growth rates held for the five years 2020-2024.

24. For example, President Clinton has recently proposed the introduction of a new "Part D" drug component of Medicare; see http://www.whitehouse.gov/WH/ New/html/Medicare/DrugCoverage/document/index.html. See also Soumerai and Ross-Degnan (1999).

\section{References}

Auster, R., and R. Oaxaca, 1981. "Identification of Supplier-Induced Demand in the Health Care Sector." Journal of Human Resources 16: 328-342.

Baker, L., and A. B. Royalty, 1999. "Medicaid Policy, Physician Behavior, and Health Care for the Low-Income Population," mimeo, Stanford University.

Board of Trustees, Federal Hospital Insurance Trust Fund, 1999. 1999 Annual Report of the Board of Trustees of the Federal Hospital Insurance Fund. Washington, DC: U.S. Government.

Chassin, M., 1993. "Explaining Geographic Variations: The Enthusiasm Hypothesis. Medical Care 31: 37-44.

Chau, D., E. Fisher, and J. Skinner, 1999. "The Importance of Regional Practice Style in a Cohort of Elderly Hip Fracture Patients," mimeo, Dartmouth Medical School.

Connors A. F, et al., 1996. "The Effectiveness of Right Heart Catheterization in the Initial Care of Critically Ill Patients." Journal of the American Medical Association 276(11) (September 18): 889-97.

Cutler, D., and L. Sheiner, 1999. "The Geography of Medicare." American Economic Review 89(2) (May): 228-233.

Escarce, J., 1992. "Explaining the Association Between Surgeon Supply and Utilization." Inquiry 29: 403-415.

Escarce, J., 1993. "Would Eliminating Differences in Physician Practice Style Reduce Geographic Variations in Cataract Surgery Rates?" Medical Care 31: 1106-1118.

Feenberg, D., and J. Skinner, 1999. "Medicare Expenditures and Medicare Taxation by State," mimeo, NBER.

Fisher, E., et al., 2000. "Associations Among Hospital Capacity, Utilization, and Mortality of U.S. Medicare Beneficiaries-Controlling for Sociodemographic Factors." Health Services Research 34(6) (February): 1351-1362. 
Folland, S., and M. Stano, 1989. "Sources of Small Area Variations in the Use of Medical Care." Journal of Health Economics 8: 85-107.

Green, L., and M. Becker, 1994. "Physician Decision Making and Variation in Hospital Admission Rates for Suspected Acute Cardiac Ischemia: A Tale of Two Towns." Medical Care 32: 1086-1097.

Gruber, J., and M. Owings, 1996. "Physician Financial Incentives and Cesarean Section Delivery." RAND Journal of Economics 27: 99-123.

Iezzoni, L. I., J. Z. Ayanian, D. W. Bates, and H. R. Burstin, 1998. "Paying More Fairly for Medicare Capitated Care," New England Journal of Medicine 339(26): 1933-8.

Kamke, K., 1998. "The German Health Care System and Health Care Reform." Health Policy 43: 171-194.

Kuttner, R., 1998. "The Risk-Adjustment Debate," New England Journal of Medicine 339(26): 1952-6.

Labelle, R., G. Stoddart, and T. Rice, 1994. "A Re-Examination of the Meaning and Importance of Supplier-Induced Demand." Journal of Health Economics 13: 347-368.

Lee, R., and J. Skinner, 1999. "Will Aging Baby Boomers Bust the Federal Budget?" Journal of Economic Perspectives 13(1): 117-140.

McClellan, M., B. J. McNeil, and J. Newhouse, 1994. "Does More Intensive Treatment of Acute Myocardial Infarction in the Elderly Reduce Mortality? Analysis Using Instrumental Variables." Journal of the American Medical Association 272 (September 21): 859-866.

McClellan, M., and J. Skinner, 1999. "Medicare Reform: Who Pays, and Who Benefits?" Health Affairs 18(1): 48-62.

Pritchard, R. S., et al., 1998. "Influence of Patient Preferences and Local Health System Characteristics on the Place of Death." Journal of the American Geriatric Society 46(10): 1242-1250.

Simon, S. R., et al., 1999. "Views of Managed Care: A Survey of Students, Residents, Faculty, and Deans at Medical Schools in the United States." The New England Journal of Medicine 340(12): 928-936.

Skinner, J., and E. Fisher, 1997. "Regional Disparities in Medicare Expenditures: An Opportunity for Reform." National Tax Journal 50(3): 413-425.

Soumerai, S. B., D. Ross-Degnan, 1999. "Inadequate Prescription-Drug Coverage for Medicare Enrollees-A Call to Action." New England Journal of Medicine 340(9): 722-8.

Stano, M., and S. Folland, 1988. "Variations in the Use of Physician Services by Medicare Benificiaries." Health Care Financing Review 9: 51-57.

SUPPORT Principal Investigators, 1995. "A Controlled Trial to Improve Care for Seriously Ill Hospitalized Patients. The Study to Understand Prognoses and Preferences for Outcome and Risk of Treatment (SUPPORT)." Journal of the American Medical Association 274: 1591-1598.

Wennberg, J. E., and M. M. Cooper (eds.), 1997. The Dartmouth Atlas of Health Care 1998. Hanover NJ: Dartmouth Medical School.

Wennberg, J. E., and M. M. Cooper (eds.), 1999. The Dartmouth Atlas of Health Care 1999. Hanover NH: Dartmouth Medical School. 
Wennberg, J., and A. Gittelsohn, 1982. "Variations in Medical Care Among Small Areas." Scientific American 246: 120-134.

Wennberg, J. E., and J. Skinner, 1999. "The Efficiency of the Medicare Program," mimeo, Dartmouth Medical School.

Zuckerman, S., W. P. Welch, and G. C. Pope, 1990. "A Geographic Index of Physician Practice Costs." Journal of Health Economics 9(1): 39-69. 